\title{
Perceptions About Data Security For Portable Storage Devices
}

Cynthia L. Knott, Marymount University, USA

G. Steube, USA

\begin{abstract}
The importance of securing data and information is a critical issue in today's world. These are no longer stored on a central system that is easy to protect and secure. Now everyone carries around small storage devices, which make guaranteeing that the information is guarded is much more complex and uncertain. This paper builds on the previous research of Knott \& Steube's in the paper Encryption and Portable Data Storage, to be published in the Spring of 2011. In the previous work we identified the potential security issues that arise from using a portable storage device such as a USB flash drive. TrueCrypt software was introduced as an option that allows users to encrypt and hide data. The TrueCrypt software, which is publically available, is particularly useful for safeguarding data on USB flash drives that are easily compromised. A survey of undergraduate students was administered which focused on their practices and attitudes about security. It was found that there were strong associations between the use of flash drives, security, and the use of passwords.
\end{abstract}

Keywords: Encryption; Security; Data Storage; Perceptions

\section{INTRODUCTION}

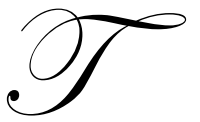

his research adds another group of interest, the faculty at Marymount University. Again, their practices and attitudes about security were gathered in a survey. The major difference in this research is that, as opposed to the previous study, the faculty group was first given an informational session and tutorial about encryption and data storage before they were asked to fill out the survey. After they were given the tutorial about the encryption process, their responses were gathered. This paper includes the results and analysis of the faculty survey that determined what habits and practices they followed with respect to securing their personal data and files. Some of the questions included in the analysis are the following:

- $\quad$ Do you encrypt your USB flash drive?

- $\quad$ Do you use any type of security for your USB flash drive?

- How important do you think security is for a flash drive?

- $\quad$ Do you use passwords to protect your USB flash drive?

- $\quad$ Do you think it is important to use security when using a USB flash drive?

- $\quad$ Do you backup your work?

- $\quad$ Do you use a flash drive while teaching in the classroom or other presentations?

- $\quad$ So you use a flash drive for transporting data?

- After seeing how to use the encryption software, are you more likely to use it to secure your USB flash drive?

The findings indicate that faculty members are concerned about their private data. They also indicated that after seeing the tutorial on the TrueCrypt software that they are more likely to encrypt their USB flash drives. We have also found that many of the faculty members have followed up with inquiries about how to ensure that their private data is secure. This paper also includes an exploratory use of discriminant analysis to determine if the questions from the survey could be used to successfully distinguish membership in the faculty and student groups based on the answers to the first six questions of the instrument. Further research could be performed to determine if 
the answers to the six questions from another group such as technology professionals could be used to distinguish among the faculty, student and professional groups.

The growing use of portable data storage devices is an accepted reality in today's society (GFI Software, 2010). One type of portable data storage device in common use today is the USB flash drive or thumb drive or memory stick (PCTechGuide, 2009). Because these drives can hold an increasing amount of data and are easily ported from one location to another, many businesses consider them to be their greatest security threat (EzineArticles.com, 2010). McAfee Labs (2010) in its 2010 threats report state:

One of the most active categories of malware this quarter was AutoRun worms (malware found on removable storage, mainly USB drives). Due to the widespread adoption of USB drives by both consumer and enterprise users around the world, this infection vector continues to be a leading source of pain. (p. 11)

This paper builds on the previous research of Knott \& Steube's in the paper Encryption and Portable Data Storage, to be published in the Spring of 2011. In the previous work we identified the potential security issues that arise from using a portable storage device such as a USB flash drive. TrueCrypt software was introduced as an option that allows users to encrypt and hide data. The TrueCrypt software, which is publically available, is particularly useful for safeguarding data on USB flash drives that are easily compromised. A survey of undergraduate students was administered which focused on their practices and attitudes about security. It was found that there were strong associations between the use of flash drives, security, and the use of passwords.

This research adds another group of interest, the faculty at Marymount University. Again, their practices and attitudes about security were gathered in a survey. The first two sections of this paper summarizes the work that was initially conducted. The third section of this report presents faculty responses about security and encryption and the fourth section compares student and faculty attitudes as expressed in the questionnaire.

\section{USING ENCRYPTION TO SECURE A USB FLASH DRIVE}

Typically flash drives are missing important encryption and authentication safeguards to protect the data (IronKey, 2007). The methods recommended in this report provide encryption and authentication through the use of a password. The solution suggested is the open source software provided by TrueCrypt Foundation (2010b); TrueCrypt's website (www.truecrypt.org) provides complete documentation for the process.

TrueCrypt software has the following advantages:

- $\quad$ Creates a virtual encrypted disk within a file and mounts it as a real disk

- $\quad$ Encrypts an entire partition or storage device such as USB flash drive or hard drive

- $\quad$ Encrypts a partition or drive where Windows is installed

- $\quad$ Encryption is automatic, real-time and transparent

- $\quad$ Parallelization and pipelining allow data to be read and written as fast as if the drive was not encrypted

- $\quad$ Encryption can be hardware-accelerated on modern processors

- $\quad$ Provides plausible deniability, in case an adversary forces you to reveal the password (TrueCrypt Foundation, 2010b)

The step by step procedure for creating an on-the-fly TrueCrypt disk is fully described on their website in the documentation section (TrueCrypt Foundation, 2010a). It is worth noting that this approach can also be used on non-USB disk drives to secure other portable and non-portable devices. As an open source solution, the software is free and readily available for download and use. After encrypting a folder on the USB flash, the existence of this folder is not visible and requires a password to mount and unhide the device. If the USB flash drive with TrueCrypt software were lost or stolen, the drive with the secured data would not be visible. The folder with the hidden information can only become visible by mounting the information through a password.

This paper recommends the use of the TrueCrypt solution for securing portable data devices and in particular its use with USB flash drives is essential. This solution provides a versatile approach for safeguarding 
such devices. In addition, this software is regularly updated to ensure its currency and usability. TrueCrypt is a reasonable answer to both individuals who wish to secure their information as well as organizations that provide portable storage devices to their employees.

The following section of this report provides data about the perceptions of users of portable storage devices in today's world. Although the risks in using unprotected portable storage devices are manifestly clear and a solution through TrueCrypt readily available it is useful to examine behaviors and attitudes toward securing portable storage units because it is these behaviors and attitudes that will ultimately determine the actions that people will take to protect their data.

\section{STUDENT PERCEPTIONS AND ATTITUDES TOWARDS PROTECTING PORTABLE STORAGE DEVICES}

To investigate current attitudes toward protecting portable data devices, a survey was administered to 63 undergraduate students in business courses at Marymount University in the Fall 2010 semester. A copy of this instrument is available in Appendix A. The overall results of the survey have been tabulated by question are in Appendix B.

The relationships among the questions used in the survey were analyzed using contingency tables with a phi coefficient to indicate the relationship among the categorical data. Phi is a chi-square based measure of association; the chi-square coefficient depends on the strength of the relationship and sample size. Since phi has a known sampling distribution it is possible to compute its standard error and significance (Howell, 2002). The PASW 19 package was used for the significance level of the computed phi value. Questions 3 and 5 had no variation in response and were not included in the phi analysis. Question 3 indicated that all participants thought that security was extremely important for a flash drive and Question 5 revealed that all participants backup their work. Consequently contingency tables were developed for Questions 1, 2, 4, and 6. Each of these questions can be represented by the variable labels listed in Table 1 .

Table 1

Questions and Labels

\begin{tabular}{cc}
\hline Question Number & Corresponding Variable Label \\
\hline 1 & Use Flash \\
2 & Use Security \\
4 & Use Passwords \\
6 & Attitude Toward Security \\
\hline
\end{tabular}

For this analysis the strength of the association will be assessed through a rule of thumb which provides a range of values for Phi and verbal assessment. Strong negative and strong positive associations are represented by Phi values between -1.0 to.-7 and .7 to 1.0, respectively. Weak negative and positive associations are between -.7 to .-3 and .3 to .7, respectively. Values of Phi indicating little or no association are between -.3 to .3 (Simon, 2005).

\section{USE FLASH BY USE SECURITY}

The relationship between using flash and security is provided in Figure 1. The Phi value was .688 and significant at the $\mathrm{p}=.05$ level. Using flash security is strongly associated with the use of security. 


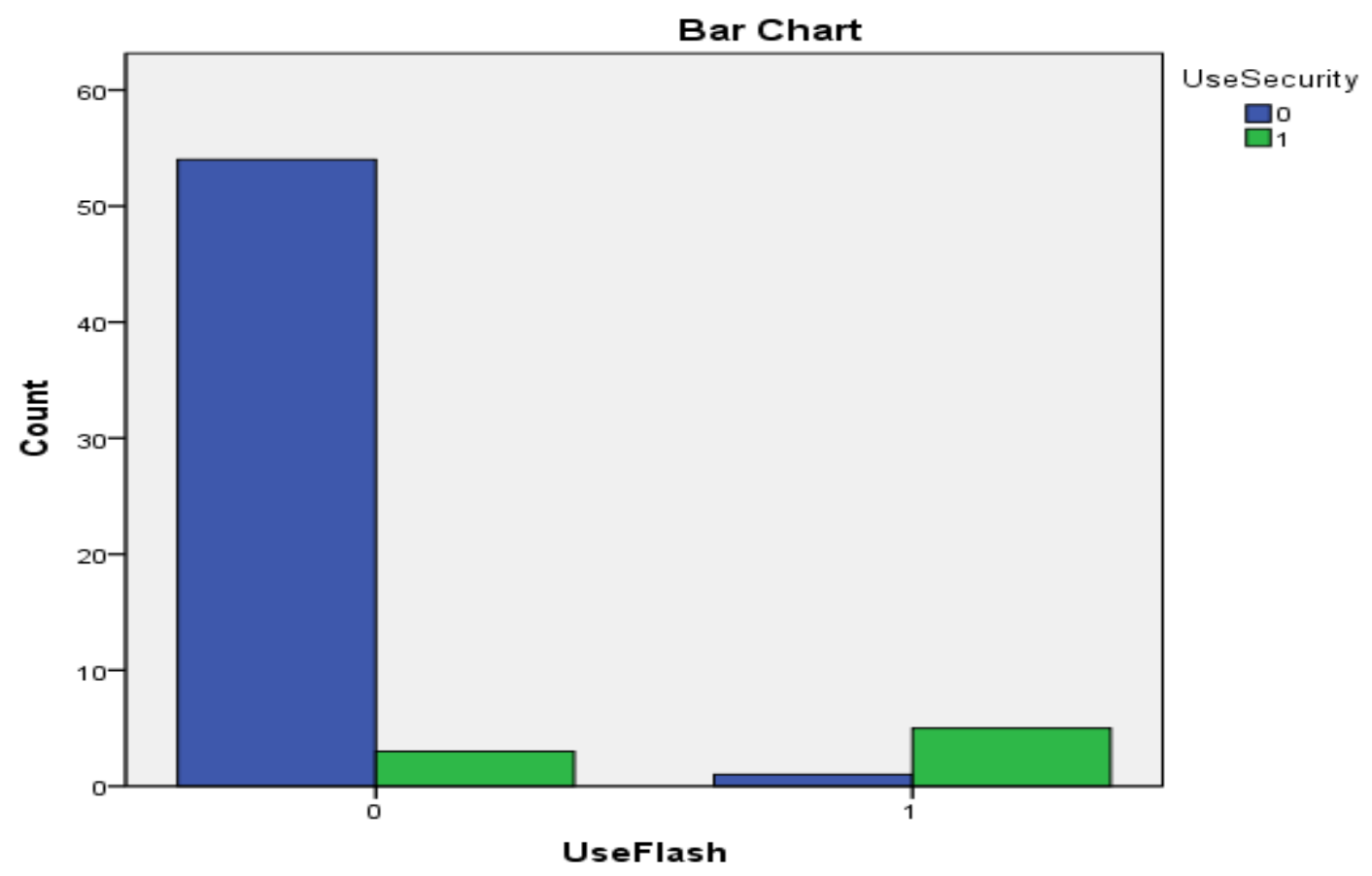

Figure 1. Use Flash by Use Security

\section{USE FLASH BY USE PASSWORDS}

The association between using flash and using passwords is presented in Figure 2. The Phi value was .574 and significant and the $\mathrm{p}=.05$ level. The use of flash is strongly related to the use of passwords.

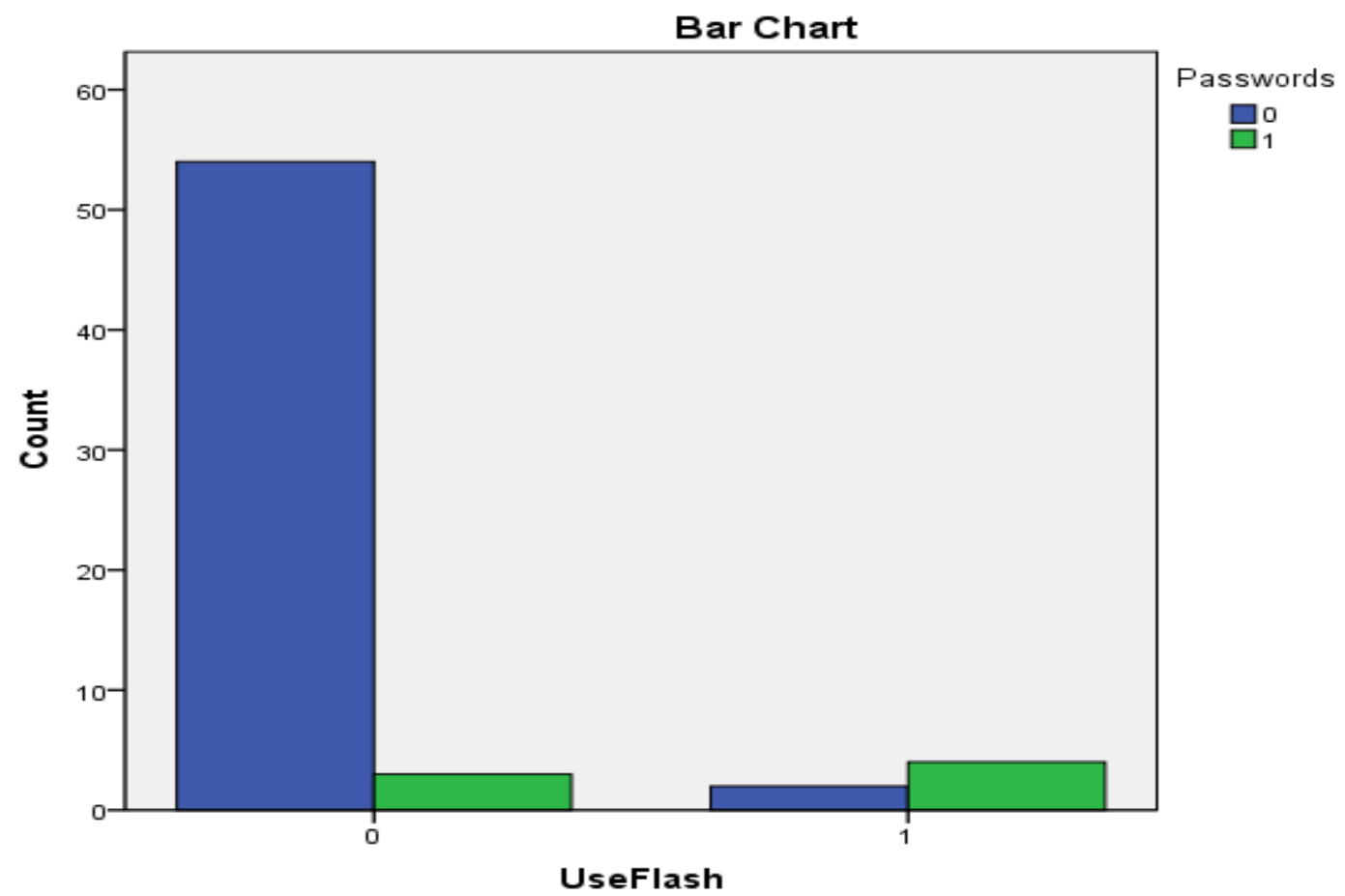

Figure 2. Use Flash by Use Passwords 


\section{USE FLASH BY ATTITUDE TOWARD SECURITY}

The relationship between using flash and attitude toward security is presented in Figure 3. The Phi coefficient was .229 and not significant at the $\mathrm{p}=.05$. The relationship between using flash drive and the attitude toward security is a weak association.

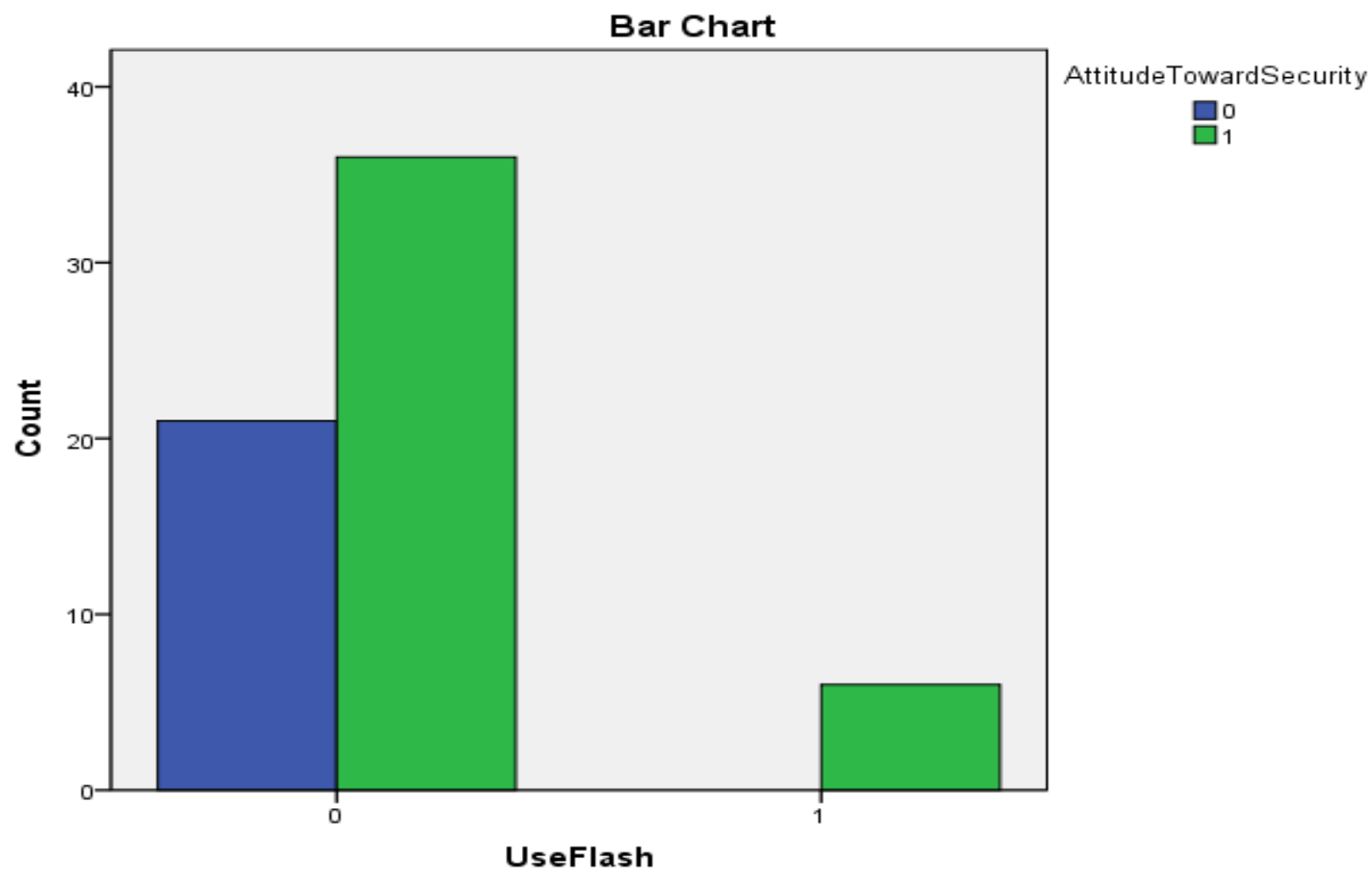

Figure 3. Use Flash and Attitude Toward Security

\section{USE SECURITY BY USE PASSWORDS}

The relationship between using security and using passwords is displayed in Figure 4. The Phi coefficient was .624 and significant at the $\mathrm{p}=.05$ level. Using security is strongly related to the use of passwords. 


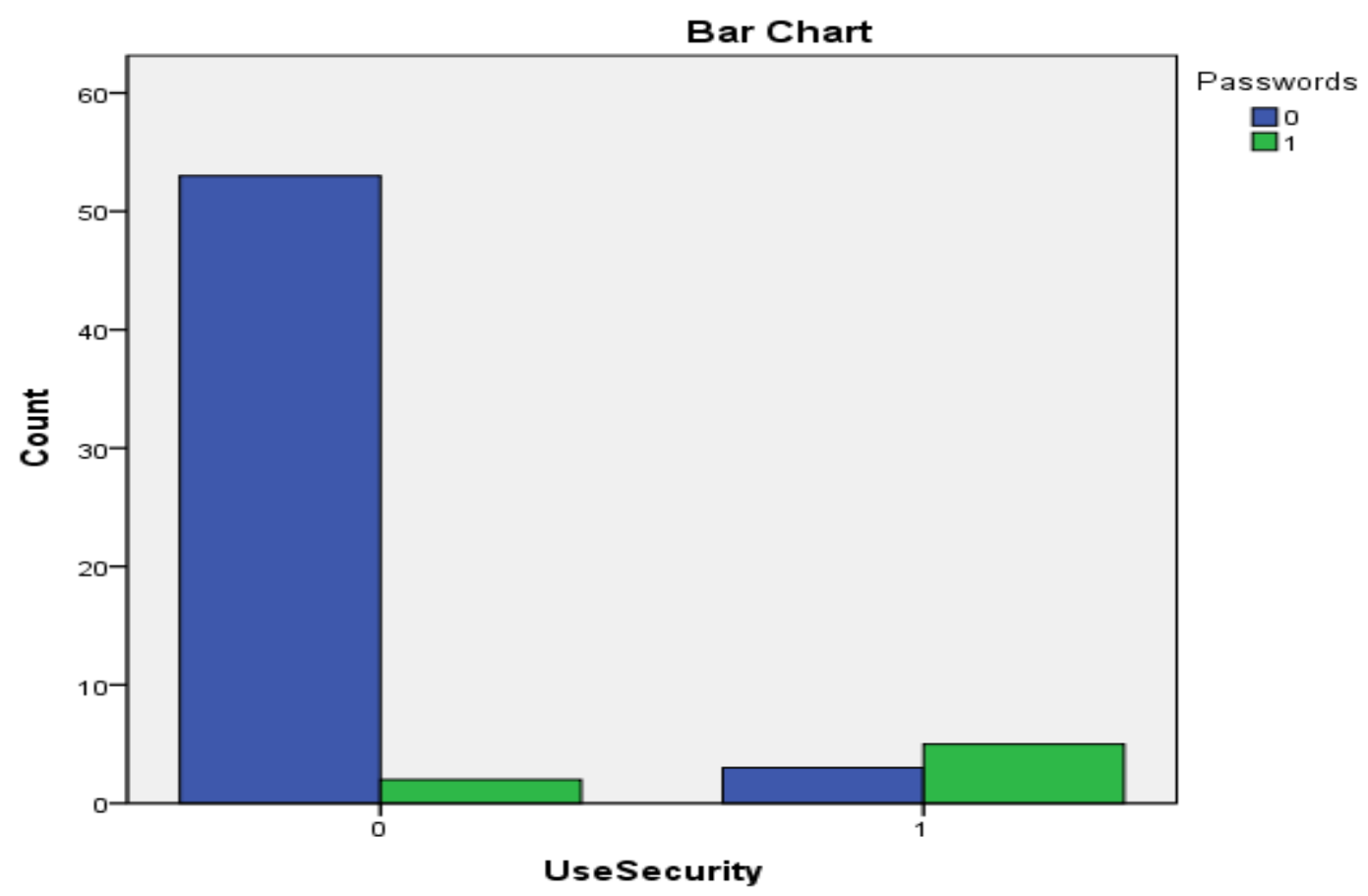

Figure 4. Use Security and Use Passwords

\section{USE SECURITY AND ATTITUDE TOWARD SECURITY}

The association between using security and attitude toward security is presented in Figure 5. The Phi coefficient was .169 and not significant at the $\mathrm{p}=.05$ level. The use of security is only weakly related to attitude toward security.

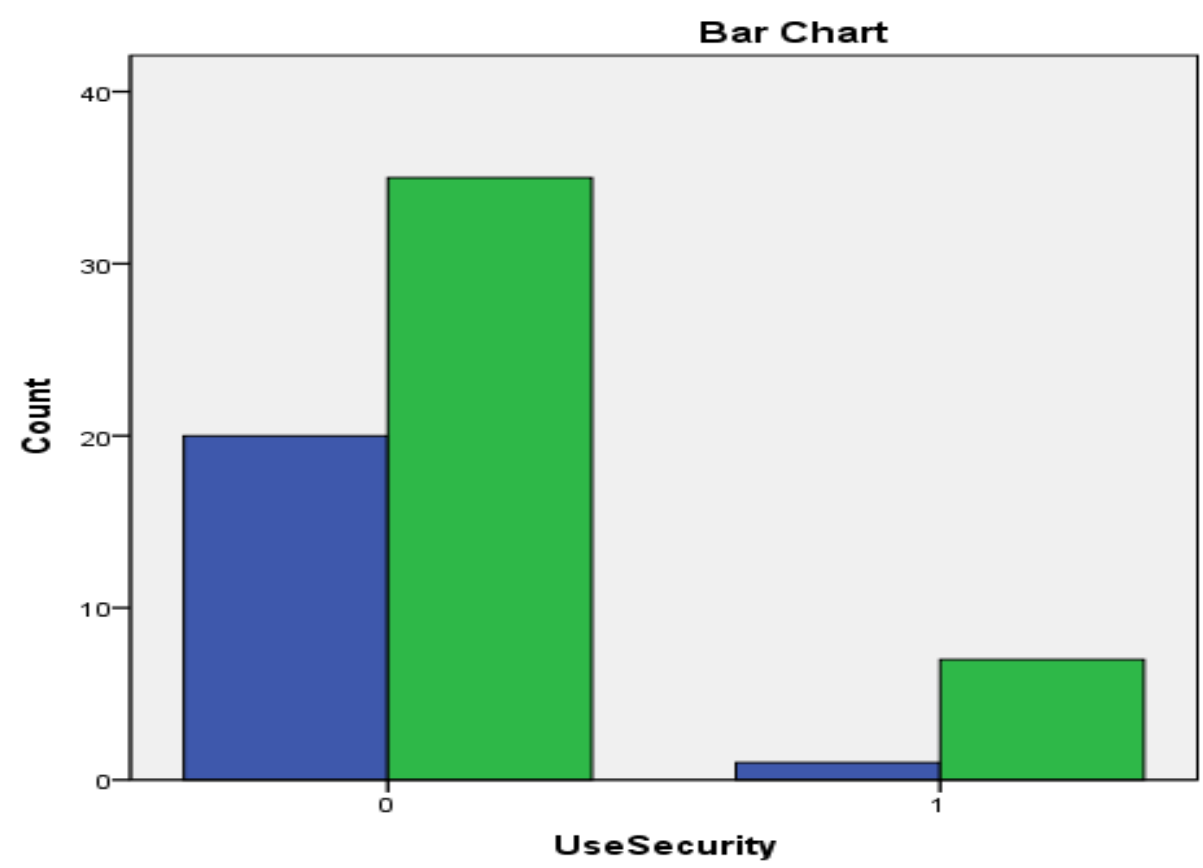

AttitudeTowardSecurity $\square 0$

Figure 5. Use Security and Attitude Toward Security 


\section{USE PASSWORDS AND ATTITUDE TOWARD SECURITY}

The association between using passwords and attitude toward security is provided in Figure 6. The Phi coefficient was .143 and not significant at the $\mathrm{p}=.05$ level. Using passwords is weakly associated with attitude toward security.

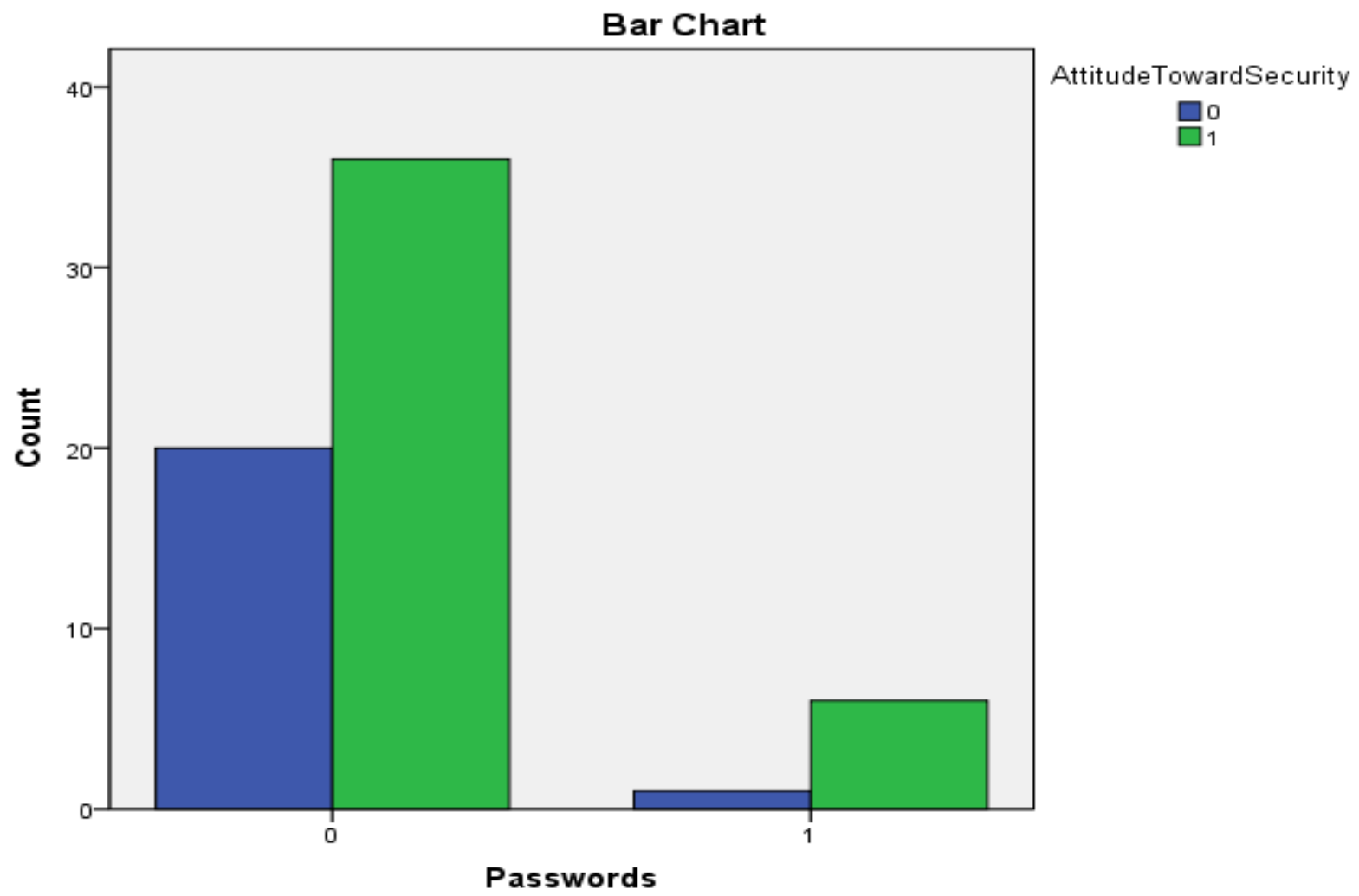

Figure 6. Use Passwords and Attitude Toward Security

\section{SUMMARY OF PHI COEFFICIENTS}

The associations for all the variables are summarized in Table 2.

Table 2

Summary of Phi Coefficients

\begin{tabular}{|c|c|c|c|c|}
\hline & $\begin{array}{l}\text { Use Flash } \\
\text { (UF) }\end{array}$ & $\begin{array}{l}\text { Use Security } \\
\text { (US) }\end{array}$ & $\begin{array}{l}\text { Use Passwords } \\
\text { (UP) }\end{array}$ & $\begin{array}{c}\text { Attitudes Toward } \\
\text { Security } \\
\text { (ATS) }\end{array}$ \\
\hline UF & 3 & $.668^{*}$ & $.574 *$ & .229 \\
\hline US & $.624 *$ & 3 & $.624 *$ & .169 \\
\hline UP & $.574 *$ & $.624^{*}$ & 3 & .143 \\
\hline ATS & .229 & .169 & .143 & \\
\hline
\end{tabular}

* = significance at the .05 level

\section{FACULTY PERCEPTIONS AND ATTITUDES TOWARD PROTECTING PORTABLE STORAGE DEVICES}

Faculty at Marymount University were surveyed about their practices and attitudes about security for portable storage devices. This group of faculty received a presentation and tutorial about the use of TrueCrypt for 
securing their USB flash drives before they completed the survey. Many of the questions used in this survey were the same as the questions posed in the student survey. The faculty survey is included in Appendix $C$ and the results of the survey are available in Appendix D.

The first six questions in the faculty survey were the same as the first six questions in the student survey. The analysis of these questions was also performed using a descriptive summary of the results because the number of respondents was 13. There was no variation in responses for questions 1 and 2. None of the participants used encryption or any other method to secure their flash drives. The importance of security for flash drives (Question 3) is available in Table 3. About 36\% felt that security was either extremely or somewhat important. Only two (15.3\%) of participants used passwords to protect their flash drives as indicated in question 4. Question 5 revealed that 12 (92.3\%) of the respondents back up their flash drives. Responses to question 6 indicated that $10(76.9 \%)$ participants believed that security for their USB drive was important.

Table 3

Question 3: How important do you think security is for a flash drive?

\begin{tabular}{lcc}
\hline Importance & Number of Responses & Percent of the Total \\
\hline Extremely important & 4 & $30.8 \%$ \\
Somewhat important & 2 & $15.4 \%$ \\
Neutral & 4 & $30.8 \%$ \\
Not very important & 2 & $15.4 \%$ \\
Not important at all & 1 & $7.7 \%$ \\
\hline
\end{tabular}

The remaining questions in the survey were unique to the faculty participants. Table 4 displays the distribution of faculty based on their school of association in the university based on the data from question 7 . The responses to question 8 showed that eleven (84.6\%) use a flash drive for classroom teaching. All respondents indicated in question 9 that they transport data with a USB device. All participants agreed that they are more likely to encrypt their portable drive after viewing the presentation on TrueCrypt.

\section{FACULTY AND STUDENT PERCEPTIONS AND ATTITUDES TOWARD PROTECTING STORAGE DEVICES}

This section compares student and faculty perceptions with regard to security for their flash drives. The comparison is done in two ways: a descriptive approach and a predictive method. The descriptive analysis examines the responses of faculty and students to the first six questions in the survey that were identical for both groups. The predictive assessment explores using discriminant analysis to investigate if the responses to questions one thru six could be used to indicate whether the respondent belongs to the faculty or student group. Can the responses be used to predict group membership?

Table 4 provides the descriptive analysis for the first six questions for both faculty and student groups. Many of the questions in this table indicate differences in attitude and practice between faculty and students. Whether this divergence is sufficiently large enough to distinguish between faculty and student group membership based on the responses is explored in the next section that explores the use of discriminant analysis.

Table 4

Descriptive Analysis of Faculty Versus Student Responses

\begin{tabular}{lll}
\hline Question & Faculty Responses & Student Responses \\
\hline 1 (Encrypt Flash) & No one encrypts their drive & $9.5 \%$ encrypt their drive \\
2 (Use Security) & No one uses security & $12.6 \%$ uses security \\
3 (Importance of Security) & (See Table 3 for details) & $100 \%$ felt that security was extremely important \\
& $\begin{array}{l}30 \% \text { felt that security was extremely } \\
\text { important }\end{array}$ & \\
4 (Use Passwords) & $15.3 \%$ use passwords & $11.1 \%$ use passwords \\
5 (Backup) & $92.3 \%$ backup their flash drives theives \\
6 (Attitude Toward Security) & $76.9 \%$ believe that security is important & $100 \%$ backup their flash drives \\
& for their flash drives & flash drives \\
\hline
\end{tabular}


The purpose of discriminant analysis is to predict group membership based on predictor variables (Tabachnick \& Fidell, 2007). Discriminant analysis is used to predict membership in naturally occurring groups rather than groups developed through random assignment. The use of faculty and student groups fit this requirement. In addition, the fact that these groups differ in size is not an issue for the analysis (Tabachnick \& Fidell). In this analysis one classification function was used that included responses to questions one thru six on both the faculty and student questionnaires. The PASW 19 statistical package used to conduct the analysis. Table 5 reveals that the Wilks's Lambda was statistically significant and the function was useful in discriminating the faculty and student group membership. Table 6 identifies the standardized discriminant function coefficients. These standardized discriminant function coefficients are equivalent to the standardized betas in regression analysis (Field, 2009); the higher the value of these coefficients the greater is their contribution to separating the groups. In this case question three contributed the most in separating the two groups. Finally the overall success in using the function to distinguish between faculty and student responses can be seen in Table 7. This table shows that the six questions were successfully in $94.7 \%$ of the cases. The cases that were classified incorrectly can be found in Appendix E shows how every instance from the 63 student and 13 faculty replies to the questions were classified.

Table 5

Wilks's Lambda

\begin{tabular}{|c|c|c|c|c|}
\hline Test of Function(s) & Wilks's Lambda & Chi-square & df & Sig. \\
\hline 1 & .416 & 62.306 & 6 & .000 \\
\hline
\end{tabular}

Table 6

Standardized Canonical Discriminant Function

\begin{tabular}{|l|l|}
\hline \multirow{2}{*}{} & \multicolumn{1}{c|}{ Function } \\
\cline { 2 - 2 } & \multicolumn{1}{|c|}{$\mathbf{1}$} \\
\hline UseFlash & -.167 \\
\hline UseSecurity & -.237 \\
\hline ImportanceOfSecurity & .950 \\
\hline Passwords & .332 \\
\hline Backup & -.187 \\
\hline AttitudeTowardSecurity & .227 \\
\hline
\end{tabular}

Table 7

Classification Results ${ }^{\text {a }}$

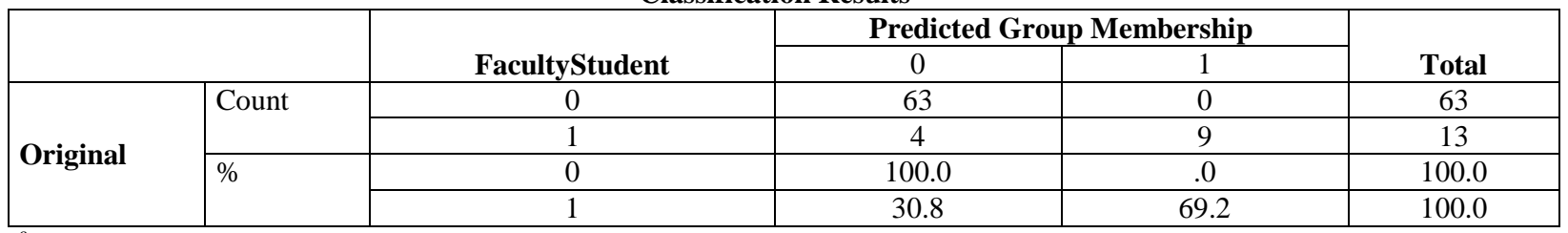

${ }^{a} 94.7 \%$ of original grouped cases correctly classified.

\section{CONCLUSION}

This paper identified portable data storage devices as potential security victims to a variety of security issues. One solution advocated in the report is the TrueCrypt software that encrypts and hides data. The TrueCrypt software is particularly useful for safeguarding data on USB flash drives that are easily compromised. Whether or not individuals opt to secure their portable data devices is a function of their attitudes toward security and their subsequent behaviors. Data was collected from undergraduate students in business classes to examine some of the attitudes and practices toward USB Flash Drives and from university faculty. It was found that there were strong associations between the use of flash drives, security, and the use of passwords for the student data. All student participants indicated that security for a flash drive was extremely important; all respondents also indicated that using security with a flash drive was important. Faculty did not use encryption or passwords to secure their flash 
drives. All students backup their drives but only $92.3 \%$ of faculty performs this action. It was also found that the first six questions in the questionnaire were useful for predicting group membership. The faculty received a presentation on how to encrypt their USB drives using TrueCrypt. Faculty in this sample unanimously agreed that they would be likely to encrypt their drives after having been shown TrueCrypt. The six questions used in both surveys appear to successfully discriminate between faculty and student responses. One suggestion for further research to administer the six questions to another group such as technology professionals to determine if these questions would useful in distinguishing among faculty, student, and professional groups.

\section{AUTHOR INFORMATION}

Dr. Cynthia Knott has been a member of the Marymount faculty since 2005. Dr. Knott teaches undergraduate and graduate courses in information systems, operations management, statistical analysis, and decision making. Dr. Knott holds an MBA and a Ph.D from The George Washington University in Washington, DC. Dr. Knott has presented her research internationally, including conferences in Chile, Turkey, Japan, and Switzerland. She has also been published in the Journal of the Operations Research Society, the Journal of the International Federation of Operational Research Societies (ITOR-IFORS), and the Journal of Applied Business and Economics. Her current research interests include quantitative methods and their application to education, business, and society. Specifically, Dr. Knott is investigating innovative ways to teach and engage students in operations research and statistical methods as well as in the area of encryption and portable data storage. She is also working in the area of health care, information technology, and marketing. She collaborates extensively with other Marymount faculty members and presents her research with these colleagues at professional conferences around the world. E-mail: cknott@marymount.edu. Corresponding author.

Dr. Gerard Steube has conducted research in a wide variety of areas including health, defense, and education. He has expertise in Information Technology and Management Science. He has participated in presentations on software complexity at major computer science conferences and conducted research that profiles computer hackers. In addition, he has provided consulting services for federal, state, and private organizations in developing information technology policies, software management plans, and outsourcing strategies. Dr. Steube provided statistical examination of Medicare and Medicaid data for the state of Maryland. He has worked on federal grants for investigating software complexity and networking and has developed software in C++, COBOL, FORTRAN, Perl, PHP, SQL, and Java. In industry he has held positions including the director of information technology, chief computer scientist, executive director of technology, director of software research, and research statistician. He was awarded the CCP (Certified Computer Professional) designation from the Institute for the Certification of Computer Professionals (ICCP) and is certified for Institutional Research Board work by the Collaborative Institutional Training Initiative. Dr. Steube is a member of MENSA and a certified MENSA test proctor; he has served as the editor for the MENSA International Journal. He serves as a reviewer and editorial board member for the Journal of Information Systems Education (JISE). Dr. Steube is a voting member in the American Psychological Association, the Mathematical Association of America, the Association for Computing Machinery, and the American Statistical Association. He is a published restoration photographer and a Web site designer. E-mail: gsteube@marymount.edu.

\section{REFERENCES}

1. EzineArticles.com. (2010). Usb drives a security threat? Retrieved November 1, 2010, from http://ezinearticles.com/?USB-Flash-Drives-a-Security-Threat?\&id=1375217

2. $\quad$ Field, A. (2009). Discovering statistics using spss (3rd ed.). Thousand Oaks, CA: SAGE Publications.

3. GFI Software. (2010). The threats posed by portable storage devices. Retrieved November 1, 2010, from http://www.gfi.com/whitepapers/threat-posed-by-portable-storage-devices.pdf

4. Howell, D. C. (2002). Statistical methods for psychology (5th ed.). Pacific Grove, CA: Duxbury/Thomson Learning.

5. IronKey, Inc. (2007). Benefits of secure usb flash drives. Retrieved November 1, 2010, from http://www.discovery.net.au/content/downld/IronKey\%20Whitepaper\%20\%20Benefits\%20of\%20Secure\%20USB\%20Flash\%20Drives.pdf 
6. McAfee Labs. (2010). Mcafee threats report: First quarter 2010. Retrieved November 1, 2010, from http://www.mcafee.com/us/local_content/reports/2010q1_threats_report.pdf

7. PCTechGuide. (2009). Definition of usb flash drive. Retrieved November 1, 2010, from http://www.pctechguide.com/glossary/WordFind.php?wordInput=USB+Flash+Drive\&input=Look+it+up\% 21\&searchType $=$ MatchWord

8. Simon, S. (2005). What is a phi coefficient? Retrieved November 2, 2010, from http://www.childrensmercy.org/stats/definitions/phi.htm

9. Tabachnick, B. G., \& Fidell, L. S. (2007). Using multivariate statistics (5th ed.). Boston: Pearson/Allyn \& Bacon.

10. TrueCrypt Foundation. (2010a). Introduction. Retrieved October 1, 2010, from http://www.truecrypt.org/docs/

11. TrueCrypt Foundation. (2010b). Truecrypt. Retrieved October 1, 2010, from http://www.truecrypt.org/

12. EzineArticles.com. (2010). Usb drives a security threat? Retrieved November 1, 2010, from http://ezinearticles.com/?USB-Flash-Drives-a-Security-Threat?\&id=1375217

13. GFI Software. (2010). The threats posed by portable storage devices. Retrieved November 1, 2010, from http://www.gfi.com/whitepapers/threat-posed-by-portable-storage-devices.pdf

14. Howell, D. C. (2002). Statistical methods for psychology (5th ed.). Pacific Grove, CA: Duxbury/Thomson Learning.

15. IronKey, Inc. (2007). Benefits of secure usb flash drives. Retrieved November 1, 2010, from http://www.discovery.net.au/content/downld/IronKey\%20Whitepaper\%20\%20Benefits\%20of\%20Secure\%20USB\%20Flash\%20Drives.pdf

16. McAfee Labs. (2010). Mcafee threats report: First quarter 2010. Retrieved November 1, 2010, from http://www.mcafee.com/us/local_content/reports/2010q1_threats_report.pdf

17. PCTechGuide. (2009). Definition of usb flash drive. Retrieved November 1, 2010, from http://www.pctechguide.com/glossary/WordFind.php?wordInput=USB+Flash+Drive\&input=Look+it+up\% 21\&searchType $=$ MatchWord

18. Simon, S. (2005). What is a phi coefficient? Retrieved November 2, 2010, from http://www.childrensmercy.org/stats/definitions/phi.htm

19. TrueCrypt Foundation. (2010a). Introduction. Retrieved October 1, 2010, from http://www.truecrypt.org/docs/

20. TrueCrypt Foundation. (2010b). Truecrypt. Retrieved October 1, 2010, from http://www.truecrypt.org/ 


\section{APPENDIX A}

\section{$\underline{\text { Survey About Encryption and Portable Data Storage }}$}

1. Do you encrypt your USB flash drive?

$$
\text { Yes No }
$$

2. Do you use any type of security for your USB flash drive?

$$
\text { Yes No }
$$

3. How important do you think security is for a flash drive?

$\begin{array}{lllll}1 & 2 & 3 & 4 & 5\end{array}$

(1-extremely important, 2-somewhat important, 3-neutral, 4-not very important, 5-not important at all)

4. Do you use passwords to protect your USB flash drive?

Yes No

5. Do you backup your work?

$$
\text { Yes No }
$$

6. Do you think it is important to use security when using a USB flash drive?

$$
\text { Yes No }
$$

7. What year in school are you?

Freshman

Sophmore

Junior

Senior 


\section{APPENDIX B}

\section{Student Survey Results}

\begin{tabular}{|c|c|c|c|c|c|c|}
\hline Q1 & Q2 & Q3 & Q4 & Q5 & Q6 & Q7 \\
\hline 0 & 0 & 1 & 0 & 1 & 1 & 3 \\
\hline 0 & 0 & 1 & 0 & 1 & 1 & 4 \\
\hline 0 & 0 & 1 & 0 & 1 & 1 & 4 \\
\hline 0 & 0 & 1 & 0 & 1 & 1 & 2 \\
\hline 0 & 0 & 1 & 0 & 1 & 0 & 4 \\
\hline 0 & 0 & 1 & 0 & 1 & 0 & 4 \\
\hline 0 & 0 & 1 & 0 & 1 & 1 & 4 \\
\hline 0 & 0 & 1 & 0 & 1 & 1 & 3 \\
\hline 0 & 0 & 1 & 0 & 1 & 1 & 4 \\
\hline 1 & 0 & 1 & 0 & 1 & 1 & 3 \\
\hline 0 & 0 & 1 & 0 & 1 & 1 & 4 \\
\hline 0 & 1 & 1 & 1 & 1 & 1 & 3 \\
\hline 0 & 0 & 1 & 0 & 1 & 1 & 3 \\
\hline 0 & 0 & 1 & 0 & 1 & 0 & 2 \\
\hline 0 & 0 & 1 & 0 & 1 & 0 & 4 \\
\hline 0 & 0 & 1 & 0 & 1 & 0 & 3 \\
\hline 0 & 0 & 1 & 0 & 1 & 0 & 4 \\
\hline 0 & 0 & 1 & 0 & 1 & 0 & 3 \\
\hline 0 & 0 & 1 & 0 & 1 & 1 & 1 \\
\hline 0 & 0 & 1 & 0 & 1 & 1 & 4 \\
\hline 0 & 0 & 1 & 0 & 1 & 0 & 4 \\
\hline 0 & 0 & 1 & 0 & 1 & 1 & 4 \\
\hline 1 & 1 & 1 & 1 & 1 & 1 & 2 \\
\hline 1 & 1 & 1 & 1 & 1 & 1 & 2 \\
\hline 1 & 1 & 1 & 0 & 1 & 1 & 1 \\
\hline 0 & 0 & 1 & 0 & 1 & 0 & 2 \\
\hline 0 & 0 & 1 & 1 & 1 & 1 & 4 \\
\hline 0 & 0 & 1 & 0 & 1 & 1 & 3 \\
\hline 0 & 0 & 1 & 0 & 1 & 1 & 3 \\
\hline 0 & 0 & 1 & 0 & 1 & 1 & 3 \\
\hline 0 & 0 & 1 & 0 & 1 & 1 & 3 \\
\hline 0 & 0 & 1 & 0 & 1 & 0 & 2 \\
\hline 1 & 1 & 1 & 1 & 1 & 1 & 2 \\
\hline 0 & 0 & 1 & 0 & 1 & 1 & 2 \\
\hline 0 & 0 & 1 & 0 & 1 & 1 & 3 \\
\hline 0 & 0 & 1 & 0 & 1 & 1 & 3 \\
\hline 0 & 0 & 1 & 0 & 1 & 1 & 3 \\
\hline 0 & 0 & 1 & 0 & 1 & 1 & 3 \\
\hline 0 & 0 & 1 & 0 & 1 & 1 & 3 \\
\hline 0 & 0 & 1 & 0 & 1 & 1 & 3 \\
\hline 0 & 0 & 1 & 0 & 1 & 0 & 3 \\
\hline 0 & 0 & 1 & 0 & 1 & 1 & 3 \\
\hline 0 & 0 & 1 & 0 & 1 & 1 & 3 \\
\hline 0 & 0 & 1 & 0 & 1 & 0 & 3 \\
\hline 0 & 0 & 1 & 0 & 1 & 1 & 4 \\
\hline 0 & 1 & 1 & 0 & 1 & 1 & 3 \\
\hline 0 & 0 & 1 & 0 & 1 & 1 & 4 \\
\hline 0 & 0 & 1 & 0 & 1 & 0 & 3 \\
\hline 0 & 0 & 1 & 1 & 1 & 0 & 4 \\
\hline
\end{tabular}


Journal of Service Science - Spring 2012

Volume 5, Number 1

APPENDIX B (Continued)

\begin{tabular}{|c|c|c|c|c|c|c|}
\hline Q1 & Q2 & Q3 & Q4 & Q5 & Q6 & Q7 \\
\hline 0 & 1 & 1 & 0 & 1 & 0 & 3 \\
\hline 0 & 0 & 1 & 0 & 1 & 1 & 3 \\
\hline 0 & 0 & 1 & 0 & 1 & 0 & 4 \\
\hline 0 & 0 & 1 & 0 & 1 & 0 & 4 \\
\hline 0 & 0 & 1 & 0 & 1 & 1 & 2 \\
\hline 0 & 0 & 1 & 0 & 1 & 1 & 4 \\
\hline 0 & 0 & 1 & 0 & 1 & 1 & 3 \\
\hline 1 & 1 & 1 & 1 & 1 & 1 & 4 \\
\hline 0 & 0 & 1 & 0 & 1 & 0 & 3 \\
\hline 0 & 0 & 1 & 0 & 1 & 1 & 3 \\
\hline 0 & 0 & 1 & 0 & 1 & 1 & 3 \\
\hline 0 & 0 & 1 & 0 & 1 & 0 & 3 \\
\hline 0 & 0 & 1 & 0 & 1 & 0 & 3 \\
\hline 0 & 0 & 1 & 0 & 1 & 0 & 3 \\
\hline
\end{tabular}




\section{APPENDIX C}

\section{Faculty Survey About Encryption and Portable Data Storage}

1. Do you encrypt your USB flash drive?

$$
\text { Yes No }
$$

2. Do you use any type of security for your USB flash drive?

Yes No

3. How important do you think security is for a flash drive?

$\begin{array}{lllll}1 & 2 & 3 & 4 & 5\end{array}$

(1-extremely important, 2-somewhat important, 3-neutral, 4-not very important, 5-not important at all)

4. Do you use passwords to protect your USB flash drive?

$$
\text { Yes No }
$$

5. Do you backup your work?

Yes No

6. Do you think it is important to use security when using a USB flash drive?

Yes $\quad$ No

7. What school are you in?

Arts \& Science $\quad$ BusinessHealth Professions $\quad$ Library

8. Do you use a USB flash drive while teaching in the classroom or other presentations?

Yes $\quad$ No

9. Do you use a USB flash drive for transporting data?

Yes $\quad$ No

10. After seeing how to use the encryption software, are you more likely to use it to secure your USB flash drive?

Yes No 
Journal of Service Science - Spring 2012

Volume 5, Number 1

\section{APPENDIX D}

Faculty Survey Results

\begin{tabular}{|c|c|c|c|c|c|c|c|c|c|}
\hline Q1 & Q2 & Q3 & Q4 & Q5 & Q6 & Q7 & Q8 & Q9 & Q10 \\
\hline 0 & 0 & 1 & 0 & 1 & 1 & 1 & 1 & 1 & 1 \\
\hline 0 & 0 & 1 & 0 & 1 & 1 & 3 & 0 & 1 & 1 \\
\hline 0 & 0 & 1 & 0 & 1 & 1 & 2 & 1 & 1 & 1 \\
\hline 0 & 0 & 4 & 0 & 1 & 1 & 3 & 1 & 1 & 1 \\
\hline 0 & 0 & 5 & 0 & 1 & 1 & 3 & 1 & 1 & 1 \\
\hline 0 & 0 & 3 & 1 & 1 & 0 & 4 & 1 & 1 & 1 \\
\hline 0 & 0 & 2 & 0 & 1 & 1 & 1 & 1 & 1 & 1 \\
\hline 0 & 0 & 4 & 0 & 1 & 1 & 2 & 0 & 1 & 1 \\
\hline 0 & 0 & 3 & 0 & 0 & 0 & 3 & 1 & 1 & 1 \\
\hline 0 & 0 & 2 & 0 & 1 & 1 & 3 & 1 & 1 & 1 \\
\hline 0 & 0 & 1 & 1 & 1 & 1 & 3 & 1 & 1 & 1 \\
\hline 0 & 0 & 3 & 0 & 1 & 0 & 2 & 1 & 1 & 1 \\
\hline 0 & 0 & 3 & 0 & 1 & 1 & 3 & 1 & 1 & 1 \\
\hline
\end{tabular}




\section{APPENDIX E}

\section{Classification Statistics}

Casewise Statistics $(0=$ student and $1=$ faculty $)$

\begin{tabular}{|c|c|c|}
\hline Case & Actual Group & Predicted Group \\
\hline 1 & 0 & 0 \\
\hline 2 & 0 & 0 \\
\hline 3 & 0 & 0 \\
\hline 4 & 0 & 0 \\
\hline 5 & 0 & 0 \\
\hline 6 & 0 & 0 \\
\hline 7 & 0 & 0 \\
\hline 8 & 0 & 0 \\
\hline 9 & 0 & 0 \\
\hline 10 & 0 & 0 \\
\hline 11 & 0 & 0 \\
\hline 12 & 0 & 0 \\
\hline 13 & 0 & 0 \\
\hline 14 & 0 & 0 \\
\hline 15 & 0 & 0 \\
\hline 16 & 0 & 0 \\
\hline 17 & 0 & 0 \\
\hline 18 & 0 & 0 \\
\hline 19 & 0 & 0 \\
\hline 20 & 0 & 0 \\
\hline 21 & 0 & 0 \\
\hline 22 & 0 & 0 \\
\hline 23 & 0 & 0 \\
\hline 24 & 0 & 0 \\
\hline 25 & 0 & 0 \\
\hline 26 & 0 & 0 \\
\hline 27 & 0 & 0 \\
\hline 28 & 0 & 0 \\
\hline 29 & 0 & 0 \\
\hline 30 & 0 & 0 \\
\hline 31 & 0 & 0 \\
\hline 32 & 0 & 0 \\
\hline 33 & 0 & 0 \\
\hline 34 & 0 & 0 \\
\hline 35 & 0 & 0 \\
\hline 36 & 0 & 0 \\
\hline 37 & 0 & 0 \\
\hline 38 & 0 & 0 \\
\hline 39 & 0 & 0 \\
\hline 40 & 0 & 0 \\
\hline 41 & 0 & 0 \\
\hline 42 & 0 & 0 \\
\hline 43 & 0 & 0 \\
\hline 44 & 0 & 0 \\
\hline 45 & 0 & 0 \\
\hline 46 & 0 & 0 \\
\hline 47 & 0 & 0 \\
\hline 48 & 0 & 0 \\
\hline 49 & 0 & 0 \\
\hline 50 & 0 & 0 \\
\hline
\end{tabular}




\section{APPENDIX E Continued}

\begin{tabular}{|c|c|c|}
\hline Case & Actual Group & Predicted Group \\
\hline 51 & 0 & 0 \\
\hline 52 & 0 & 0 \\
\hline 53 & 0 & 0 \\
\hline 54 & 0 & 0 \\
\hline 55 & 0 & 0 \\
\hline 56 & 0 & 0 \\
\hline 57 & 0 & 0 \\
\hline 58 & 0 & 0 \\
\hline 59 & 0 & 0 \\
\hline 60 & 0 & 0 \\
\hline 61 & 0 & 0 \\
\hline 62 & 0 & 0 \\
\hline 63 & 0 & 0 \\
\hline 64 & 1 & $0 * *$ \\
\hline 65 & 1 & $0 * *$ \\
\hline 66 & 1 & $0 * *$ \\
\hline 67 & 1 & 1 \\
\hline 68 & 1 & 1 \\
\hline 69 & 1 & 1 \\
\hline 70 & 1 & 1 \\
\hline 71 & 1 & 1 \\
\hline 72 & 1 & 1 \\
\hline 73 & 1 & 1 \\
\hline 74 & 1 & $0 * *$ \\
\hline 75 & 1 & 1 \\
\hline 76 & 1 & 1 \\
\hline
\end{tabular}

** Misclassified case 